\title{
Intravascular Ultrasound
}

National Cancer Institute

\section{Source}

National Cancer Institute. Intravascular Ultrasound. NCI Thesaurus. Code C99535.

An invasive procedure in which sound waves (called ultrasound) are bounced off of vascular tissues from within the vessel and the echoes produce a picture (sonogram). 